\title{
Positive Deviance and Leadership: An Exploratory Field Study
}

\author{
Willem Mertens \\ Queensland University of Technology \\ w.mertens@qut.edu.au
}

\author{
Jan Recker ${ }^{1}$ \\ Queensland University of Technology \\ j.recker@qut.edu.au
}

\begin{abstract}
Positive deviance refers to behavior that deviates from the norms of the reference group and has positive effects on the organization. It is an endogenous source of organizational creativity that has been shown to be powerful tool for learning and change. Despite growing interest, little remains known about the factors that stimulate positive deviance; in particular, how management can enable its emergence. In this paper, we explore the relationship between leadership and positive deviance through a conversion mixed methods field study of two hierarchical layers of store management in a large Australian retailer. Our findings indicate that management can best enable the emergence of positive deviance by combining empowering leadership behaviors with adequate levels of contingent reward and monitoring behaviors. These findings suggest that, depending on the frame of reference, positive deviance may emerge as a source for innovation that is endogenous to routines, rather than deviance from routines.
\end{abstract}

\section{Introduction}

In order to remain competitive, organizations have to continuously optimize and reinvent their products and services, while at the same time increasing the efficiency and predictability of work by establishing stable routines [54]. These two strategies, routinization and innovation, are often considered to be mutually exclusive. Routinization is assumed by many to reduce the space for creativity and change, and innovation is often seen as a variation from established routines [13]. One promising way of how organizations can accelerate creativity and innovation while retaining routines is by learning from Positive Deviants [15, 32]: people who fail to follow the organizational norms and routines, and are successful because of it [48]. A growing body of research corroborates the validity of the positive deviance construct and its innovation potential [e.g., 15, 29, 42, 48, 50] and many have investigated possible antecedents of positive deviance (for an overview, see $[29,48]$ ).
A common assumption in most of these studies is that positive deviance emerges spontaneously, with elements of the environment, the person or the interaction between both making this emergence more or less likely. However, some argue that positive deviance can also actively be stimulated by leaders. Pascale and Sternin [32] propose that leaders should "fan the flames" of people that already positively deviate, while other research suggests that there are certain leadership styles and behaviors that may actively stimulate positive deviant behavior; for example, transformational leadership [42, 48], information sharing and transparency, articulating inspiring visions and stimulating employee latitude [24], and instilling a sense of psychological empowerment in employees [29, 43, 48]. We attempt to unpack these oscillating views through an empirical study of positive deviance under the regime of different leadership behaviors. Our aim is to find out which leadership behaviors do indeed stimulate the emergence of positive deviance, and how.

Because of the exploratory nature of this question and the wealth of possibly important leadership behaviors, we conducted a mixed methods field study situated in the retail domain. In this paper, we report on the findings from this study. We first provide a brief overview of previous research on positive deviance and its determinants, focusing our attention on leadership. Next, we describe the design and execution of our study and then propose an explanatory multi-level model of positive deviance, which suggests that positive deviance can be stimulated by a well-balanced mix of transactional and empowering leadership.

\section{Background}

Positive deviance describes behavior that (1) deviates from the norms of a reference group, (2) is positive in terms of intention or effects and (3) conforms to hypernorms-i.e., is not harmful for other groups or society as a whole $[28,48]$. Norms are rules that regulate and regularize behavior [2, 11]. A growing body of literature reports on positive deviance in various domains, analyzing cases such as nursepatient communication [22], adaptive leadership [25], a high risk nuclear clean-up [24], environmentally 
conscious organizational boards [49] and exceptional bakers [29].

Many have theorized about what stimulates the emergence of positive deviance in organizations. To organize our review of this literature, we used the framework that Cordery and Parker [7] introduced to summarize the research on the psychological impact of work design. Situational antecedents include task, relational and contextual characteristics. Psychological states or processes are changeable individual characteristics such as one's motivation or engagement. Personal antecedents are more stable factors related to personality and personal attitudes that are often found to mediate the effect of the situation on psychological states and behavior. Table 1 shows our interpretation of the literature on positive deviance on basis of this framework.

Table A.1. Non-exhaustive overview of documented determinants of positive deviance

\begin{tabular}{|c|c|c|c|}
\hline Antecedent & & $\begin{array}{l}\text { References of } \\
\text { related literature }\end{array}$ & $\begin{array}{l}\text { Methods used to } \\
\text { derive result }\end{array}$ \\
\hline \multirow{5}{*}{$\begin{array}{l}\text { Situational } \\
\text { antecedents }\end{array}$} & access to information*, access to resources & {$[15]$} & Quantitative (survey) \\
\hline & employee latitude & {$[37]$} & Conceptual \\
\hline & $\begin{array}{l}\text { transformational leadership, supervisor support and openness, } \\
\text { non-controlling supervision, leader-member exchange, } \\
\text { organizational culture and climate, organizational support, } \\
\text { procedural justice, group culture and norms, co-worker support }\end{array}$ & [48] & $\begin{array}{l}\text { Conceptual (literature } \\
\text { review) }\end{array}$ \\
\hline & $\begin{array}{l}\text { collective leadership, information sharing and transparency, } \\
\text { focus on integrity and trust, articulating an aspiring vision, } \\
\text { cultural change, stimulating meaning }\end{array}$ & {$[24]$} & Qualitative \\
\hline & network centrality*, experience of the board of directors* & {$[49]$} & Quantitative \\
\hline \multirow{5}{*}{$\begin{array}{l}\text { Psychological } \\
\text { states or } \\
\text { processes }\end{array}$} & psychological empowerment* & {$[29,48,43]$} & $\begin{array}{l}\text { Conceptual and } \\
\text { Qualitative }\end{array}$ \\
\hline & intrinsic motivation, meaning, personal efficacy & [41] & Conceptual \\
\hline & $\begin{array}{l}\text { intrinsic motivation, felt obligation, attachment to group, } \\
\text { positive job attitudes }\end{array}$ & {$[48]$} & $\begin{array}{l}\text { Conceptual (literature } \\
\text { review) }\end{array}$ \\
\hline & passionate commitment to social or moral purpose & [37] & Conceptual \\
\hline & organizational trust ${ }^{*}$, perceived organizational support* & [23] & Quantitative (survey) \\
\hline \multirow{8}{*}{$\begin{array}{l}\text { Personal } \\
\text { antecedents }\end{array}$} & workaholism* & {$[14]$} & Quantitative (survey) \\
\hline & Machiavellianism*, role breath self-efficacy* & {$[15]$} & Quantitative (survey) \\
\hline & holistic approach to resource use, better risk management & {$[37]$} & Conceptual \\
\hline & courage, other-focus & {$[41]$} & Conceptual \\
\hline & $\begin{array}{l}\text { self-worth, efficacy of action, extraversion, proactive } \\
\text { personality, innovative cognitive style }\end{array}$ & {$[48]$} & $\begin{array}{l}\text { Conceptual (literature } \\
\text { review) }\end{array}$ \\
\hline & $\begin{array}{l}\text { facilitative communication*, active communication*, technical } \\
\text { information-giving*, tailored information-giving*, solicited } \\
\text { information-giving*, giving elaborate information*, giving } \\
\text { unsolicited information*, asking questions*, use of } \\
\text { communication aids, motivation, self-efficacy, role } \\
\text { expectations, knowledge and skill }\end{array}$ & {$[22]$} & Qualitative \\
\hline & $\begin{array}{l}\text { being forgiving, being grateful, being energizing, being } \\
\text { savoring, being over-performing }\end{array}$ & {$[21]$} & Conceptual \\
\hline & service orientation & [29] & Qualitative \\
\hline
\end{tabular}

* signifies that empirical support was found for the suggested effect. Note: antecedents printed in bold refer to dimensions of psychological empowerment; antecedents printed in italic refer to leadership behaviors or situational antecedents that have also been linked to psychological empowerment [36, 44]. 
The main recurrent theme in the literature that Table 1 highlights in bold are the many references in the literature to employee latitude, intrinsic motivation and psychological empowerment [39]. Psychological empowerment is a motivational concept that is of central importance in mediating the effects of the work context on employee behavior and attitudes [36, 44, 26]. It refers to a set of psychological states that are necessary for individuals to feel in control over their work [44], characterized by perceiving work as meaningful, believing in one's own competence with regards to the work, and having a sense of selfdetermination (i.e., intrinsic motivation) and control over work outcomes [39]. Because of that sense of meaning and self-determination, it has been hypothesized that empowered people will want to do their jobs as good as possible, and will deviate from rules or norms if that will allow them to execute their work in the best possible way [48, 29].

Psychological empowerment, in turn, has been associated with a range of leadership styles and behaviors $[44,36]$; some of these are highlighted in italic font in Table 1. For example, in an influential study on positive deviance, Vadera et al. [48] proposed that employee empowerment leads to positive deviance, and that empowerment can be stimulated by transformational leadership behaviors: inspirational motivation, idealized influence, individualized consideration, and intellectual stimulation. They argue that these behaviors demonstrate to employees that honesty poses no risk, which creates the psychological safety and strength that allows employees to engage in positive deviance. Other leadership behaviors that have been related to this fortification of the individual and to psychological empowerment, are empowering leadership behaviors [1]: participative decision making, showing concern/interacting with the team, leading by example, informing, and coaching.

By contrast, some leadership behaviors may reduce the emergence of positive deviance. One good example are behaviors subsumed under transactional leadership. Transactional leadership is generally perceived as a tool to influence compliance; it is characterized by an exchange of leader rewards for productive employee behavior, and sanctions for undesirable behavior [4].

Typically, transactional and transformational leaderships are believed to be additive: transactional leadership forms a basis upon which transformational leadership behaviors build [17]. However, they provide an orthogonal logic for the explanation of deviance: transactional leadership focuses the attention towards doing the right thing, while transformational leadership focuses on achieving the best results. Positive deviance is about not doing what is typically considered 'right' in order to achieve the best result; therefore, it is situated in a nexus where transactional and transformational leadership may not additive but instead conflicting.

In other words, it remains underexplored how psychological empowerment and common leadership behaviors relate to positive deviance, which is why we unpack this question empirically.

\section{Research Method}

\subsection{Setting}

We conducted our study in a large international retail organization headquartered in Australia. The organization is ranked as one of the 25 largest retailers globally and employs over 180,000 staff, amongst others in a network of - at the time -952 grocery stores within Australia. Our chosen units of analysis were these stores. Stores vary in size, but typically include a range of trading departments such as seafood, deli, long life and bakery.

The management structure of these stores is typically built up of three main layers: at the head are one store manager and his assistant store manager. They lead a team of department and assistant department managers. The members of this team, in turn, each manage one of the departments in the store.

All stores operate according to the same model and the in-store work processes are highly standardized across stores. Where explicit descriptions are not available, work routines are heavily normalized due to the high level of rotation of personnel between stores and the tight collaboration between store managers within the same area (a group of around 18 stores). Despite this high level of standardization and routinization, the performance of the stores shows a large variation that cannot solely be explained on the basis of extraneous variables such as store size, location and customer base. Thus, it was hypothesized that these performance differences were at least in part caused by positive deviant behavior.

In this study, positive deviant behavior was operationalized as behavior that is engaged in with positive intentions, that deviates from the norms of the organization (the reference group) and that contributes to the organizational performance (the benefit) without negatively affecting society as a whole (i.e. conforms to hypernorms) [28]. This means that on top of conformance to hypernorms and the positive intent that is considered a sufficient condition for calling deviance 'positive' by one stream of research $[15,42,50]$, we follow [29, 48] and add the necessary condition that it has to produce a positive effect, i.e. an increase in performance. In what follows, we discuss the design 
and execution of our study of positive deviance and its enablers.

\subsection{Design: mixed method field study}

The design of our study follows existing guidelines for mixed methods research [45] and can best be described as a conversion mixed methods design. Data was gathered through qualitative case studies, but analyzed using both qualitative and quantitative methods. This means that the qualitative data was converted into quantitative data. The detailed design of our study is presented in Figure 1.

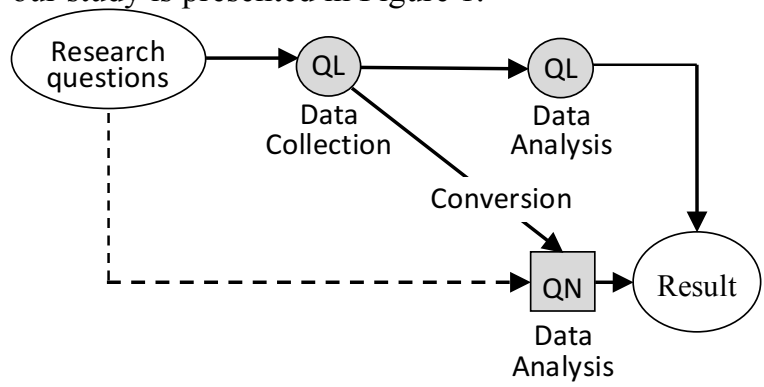

Figure 1. Detailed study design; adapted from [46] (QL = qualitative, $\mathrm{QN}=$ quantitative)

We start by identifying and qualitatively studying a number of stores where positive deviance is most likely to occur: stores that perform exceptionally well in comparison to the reference group (other units of the same type) (Data Collection). Next, we analyze the data both qualitatively and quantitatively in search for behaviors that deviate from the organizational norms and plausible enablers of this behavior (Data Analysis). In the discussion, we compare the inductively derived empirical results to the leadership literature and evaluate the extent to which our findings complement previous theories, where our results are dissimilar from previous research and whether our conclusions allow generating new theory [34].

\subsection{Data Collection}

3.3.1. Sampling design and participants. The objective of this study was to explore the existence of positive deviance in the store network and to find out if and how leadership behaviors exhibited by store management enabled positive deviance where it existed. To this end, we first relied on purposive sampling [8] to select a sample of stores in which we estimated the chance of observing positive deviance to be highest: stores that perform exceptionally well.

We defined performance on the basis of measures in the balanced scorecard [19] used by the case organization to evaluate the performance of their stores. We examined 25 performance metrics categorized into dimensions: customers (e.g. NetPromotor Score, basket size), operations (e.g. shrinkage), investors (e.g. sales, wages to sales), people (e.g. turnover, engagement), and community and environment (e.g. fundraising, safety). This balanced set of measures includes input measures (e.g. wages) as well as output measures (e.g. sales), but relatively little information on exogenous factors (e.g. location, customer base, retail surface space) [10].

We first explored how these external factors influence performance. As the data showed that recent store opening and refurbishments have a profound influence on performance, we excluded stores that had been opened or refurbished within the previous five years $(n=349)$. We also controlled the data for retail surface space and variations that are related to local and seasonal variation. We aggregated the monthly scores to a single score for the financial year 2013 and used percentiles rather than raw scores.

On the basis of these measures, we selected a sampling frame of 72 out of the 603 stores that consisted of:

- 30 stores that scored at or above the $98^{\text {th }}$ percentile (pc.98) on one of the five performance dimensions and between pc. 25 and pc.75 on all other dimensions ( $n=6$ for each of the five dimensions),

- 30 stores that scored below pc.02 on one of the five performance dimensions and between pc. 25 and pc.75 on all other dimensions $(n=6$ for each dimension),

- six stores that scored highest on all five dimensions combined, and

- six stores that scored lowest on all five dimensions.

This sampling approach allowed us to link behavioral differences between stores to specific differences in performance across the five dimensions. Figure 2 illustrates different combinations of metrics that-when taking into account the five performance dimensions-sum up to 12 possible performance profiles.

From this sampling frame, the final subsample of 17 stores that was subjected to in-depth case study was selected based on their contextual comparability (e.g. demographics of local customer population, location), their equal spread across Australian states, their accessibility (e.g., stores from Western Australia and stores located in the outback were excluded for practical reasons), and based on theoretical considerations. This aspect of theoretical sampling [8] will be described in the next section: procedures. 


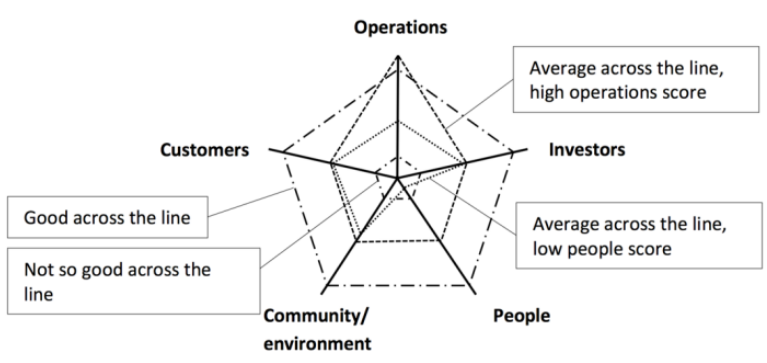

Figure 2. Illustration of the store selection based on store performance as measured by the case organization's application of the balanced scorecard [34].

3.3.2. Procedures. The case studies were executed jointly by two researchers and approached as naively as possible in terms of the 'gestalts' of leadership behavior (e.g. transactional, transformational), but with a good understanding of the different lower-level categories of possible leadership behaviors that have been described in the literature. We used the hierarchical taxonomy of leadership behaviors as proposed by Yukl [51] as a guide. The taxonomy includes 15 behaviors grouped into four categories: task-oriented, relations-oriented, change-oriented and external leadership behaviors. Apart from these leadership behaviors, the researchers focused on occurrences of positive deviance (deviance with good intention that may explain performance differences) and on anything else they encountered that could explain the emergence of positive deviance and/or the observed performance differences.

Each case study was conducted according to the same procedure. First, the researchers entered the store as customers to grasp the general atmosphere (for about 10 minutes). They were at that point blind to the performance profile of the store. Next, they introduced themselves to the staff and explained the purpose of the visit and ethical concerns. Store employees and management were also kept blind to the performance profile and the importance of the performance dimensions; the cover story referred to an interest in operational and behavioral differences between stores and the influence of the manager on those differences. Next, the researchers observed on-the-job behavior, listened to conversations, attended meetings, asked questions about a variety of topics and interviewed the store manager, the assistant store manager, and available department managers and lower-level staff members (for approximately 2 hours). Based on these observations and interviews, the researchers then withdrew and predicted the data profile based on their observations. After checking the correctness of their estimates and making sense of their observations based on the data, they went back into the store to further increase their understanding by means of more observations and interviews and to document some of the observed differences in lay-out of meeting rooms and communication blackboards (up to three more hours). All interviews and observations were captured in detailed research notes by both researchers and these notes were aggregated and completed on the same day of each case study.

The researchers' joint performance prediction was accurate in about 7 out of 10 cases. When inaccurate, they selected another store with a similar profile to increase their understanding (i.e. theoretical sampling). Based on this approach, a total of 17 stores from the sampling frame were subjected to an in-depth case study. No case study could be conducted for two out of the 12 possible performance profiles: none of the stores in the lowest range for the people and for the community and responsibility dimension was both accessible and willing to cooperate.

\subsection{Data Analysis}

The collected data consisted of over 300 pages of notes (A5) and over 70 pictures of in-store communication posters and store layout. The research notes and information captured in images were analyzed both qualitatively and quantitatively.

In a first step, all gathered data was coded and analyzed qualitatively: codes were inductively derived from the data [27] according to relevant guidelines on open coding [5, 47]. The goal of this grounded coding was two-fold. First, it served as a systematic way to gather stories, group these stories into trends, understand relations between observed variables and trends, separate out extraneous from independent factors, and in general to understand behavior in its context. Second, it served to create a coding tree that formed the basis for the quantitative analysis of the data. The coding tree consisted of 134 open codes which, through constant comparison, were grouped into 13 categories.

The quantitative analysis consisted of intensity axial coding [3]: all data was re-assessed in light of the coding tree and converted into quantitative data [46] by allocating a score between 1 and 5 to each code for each of the cases. This score represented the intensity with which a certain code had presented in that certain case study. A case would score a 1 on, e.g., leading by example if the store manager had not been observed to be leading by example and if the staff reported to never observe this behavior in their store manager either. A 5 was only allocated when the researchers had observed strong levels of the behavior themselves. If no evidence was available in the data, no score was 
allocated. Finally, this quantified data was combined into one dataset with the store-level performance data; Table 1 illustrates the structure of this dataset.

In a next step, the scores for all codes (excluding the ones where less than five scores were available) were correlated with the performance dimensions. Only the $10 \%$ codes with the highest correlation to each of the performance dimensions and the $10 \%$ codes with the lowest correlation to each of the performance dimensions were retained. This list of codes was again grouped into higher-level dimensions and validated in a one-and-a-half-hour workshop with a group of eight domain experts. The purpose of this workshop was to test the content validity of our open codes, evaluate whether the categories accurately grouped the codes, and assess the validity of our interpretation of the relations between different codes. The group was broken up in two groups for the first hour with a researcher available to answer questions and take notes in both groups. In the second part of the workshop we discussed subgroup findings with the entire group.

Table 1. Illustration of the structure of the converted (i.e. quantified) data

\begin{tabular}{llccc}
\hline & & \multicolumn{3}{c}{ Cases } \\
\hline Categories & Open codes & Case1 & Case2 & Case3 \\
\hline Communication & Informative & 1 & 3 & N/A \\
& Bottom-up & 2 & 2 & 5 \\
& $\ldots$ & $\ldots$ & $\ldots$ & $\ldots$ \\
$\begin{array}{l}\text { Leadership } \\
\text { behavior }\end{array}$ & $\begin{array}{l}\text { Micro } \\
\text { managing }\end{array}$ & 4 & N/A & 1 \\
& $\begin{array}{l}\text { External } \\
\text { networking }\end{array}$ & 4 & 4 & 1 \\
& $\ldots$ & $\ldots$ & $\ldots$ & $\ldots$ \\
\hline Scorecard & Metric & \multicolumn{2}{c}{ Performance (Pc) } \\
Dimension & $\begin{array}{l}\text { Profit } \\
\text { Investors }\end{array}$ & .65 & .55 & .47 \\
& $\begin{array}{l}\text { Wages to } \\
\text { sales }\end{array}$ & .44 & .07 & .60 \\
& $\ldots$ & $\ldots$ & $\ldots$ & $\ldots$ \\
\hline
\end{tabular}

This combination of qualitative analysis, quantitative analysis and a workshop with domain experts allowed us to drastically reduce the bias introduced by the researchers during the data gathering and coding and to come up with an integrative interpretation of our validated lists of codes and stories.

\section{Findings}

In this paper we explored how leaders enable the emergence of positive deviance. Through 17 in-depth case studies, we derived a range of findings that point at multiple influencing factors at multiple organizational levels. In this section, we will discuss these results in light of existing theory and previous research. We seek to explore, first, how our findings complement previous research and can be interpreted in the light of previous theory [36]. Second, we will highlight how our results differ from and add to previous research within the domain of positive deviance, and we will seek inspiration outside of that domain to explain these dissimilarities and to develop the integrative theoretical model that is presented in Figure 3 and that explains our most important findings.

The result of the quantitative analysis of the qualitative data was a final list of 69 open codes that were found to be related to the various performance dimensions. The 69 codes were structured in 10 categories: communication, corporate social responsibility, customer engagement, internal corporate relations, operational management, people's backgrounds, leader attitudes, leadership behaviors, leadership team dynamics, and work atmosphere. This list of codes was combined with the results of the qualitative analysis of the data to provide context and to relate the codes. From this analysis, a number clear findings emerged.

First, we recognized - in store managers as well as their team members - the frequently suggested importance of self-determination [20, 47], of feeling in charge and having that active orientation towards work that is captured by the dimensions of psychological empowerment [29, 39, 43, 48]: "I run this store like it's my own". Contrary to what Vadera et al. [48] suggest, we did not encounter any effects of felt obligation, but this is not easily observed and we did not specifically probe for it in our interviews. We did observe an influence in store managers of feeling strongly and emotionally bound to the cause of the organization, which is generally referred to as a strong affective organizational commitment [30, 53]. "[our company] is a great Australian company!", "we change the lives of so many Australian people”. This commitment has not been previously related to positive deviance, but it has been found to mediate the effect of psychological empowerment and work experience on other positive organizational behavior [9, 31].

The leaders' psychological empowerment, in turn, affected the degree to which they engaged in positive deviant behavior and empowering leadership behavior. In line with previous research $[15,42,48]$, we found that more strongly empowered leaders more frequently deviated from the rules and norms of the organization in order to achieve their goals and optimize the in-store operations and/or atmosphere: "do it and ask for forgiveness, rather than not do it at all". 
Their deviant behavior, in turn, 'contaminated' their team members to also engage more frequently in positive deviant behavior. The leaders also enabled them to do this through leadership behaviors that aimed to empower the team members. In other words, their own empowerment cascaded down the line [35, $44,40]$. Specifically, they engaged more frequently in the five leadership behaviors that characterize empowering leadership [1]:

- $\quad$ involving team members in decision making: "I don't make many decisions in [my store]", "many of the staff know more about the business than I do"

- $\quad$ showing concern and frequently interacting with the team: "all people come in with good intentions", "treat people how you want to be treated"

- leading by example by working with them on the shop floor: "if I can't do it, how can I tell my staff to do it", " "they know that you know what you are doing when you work with them; the more you do that, the less they can run over you"

- extensively informing them of the what and why of company decisions: ": "my role is to understand the strategy of the company and to make sure that my team understands all that"

- coaching them in their work and leadership: "it's about teaching the thought process to people", "give someone a fish and they'll eat, teach them how to fish and they'll eat forever"
In line with previous research [e.g. 6, 9, 12, 52], this in turn increased the psychological empowerment of team members: where the store management actively involved them, kept them informed, invested time and effort in training and coaching and provided clear directions, they also adopted a more active work orientation, felt in charge and responsible for their own work, and strived to have an impact. This more active and autonomous work orientation also influenced their behavior to be more autonomous and focused on getting the job done, "do[ing] what is right, not what is easy", and solving the problem rather than following the rules (i.e., positive deviance).

However, we also found that in certain aspects of the work, objectively successful managers placed an equally strong emphasized on compliance to procedural norms: "you must do the routines every day, no ifs, buts or wonts". This was particularly the case for work routines that were related to food safety, customer safety and stock replenishment. In these work domains, successful managers enacted the norms very strictly by monitoring the behavior of their team and by contingently rewarding or punishing (non-)compliant behavior; behaviors that are at the heart of transactional leadership [33]. Whereas the relation between these behaviors and empowering behaviors is not documented in the literature, they appeared to interact in their effects on followers. The combination of strong transactional leadership behaviors, which provide structure and predictability, and high levels of empowerment where possible especially appeared to

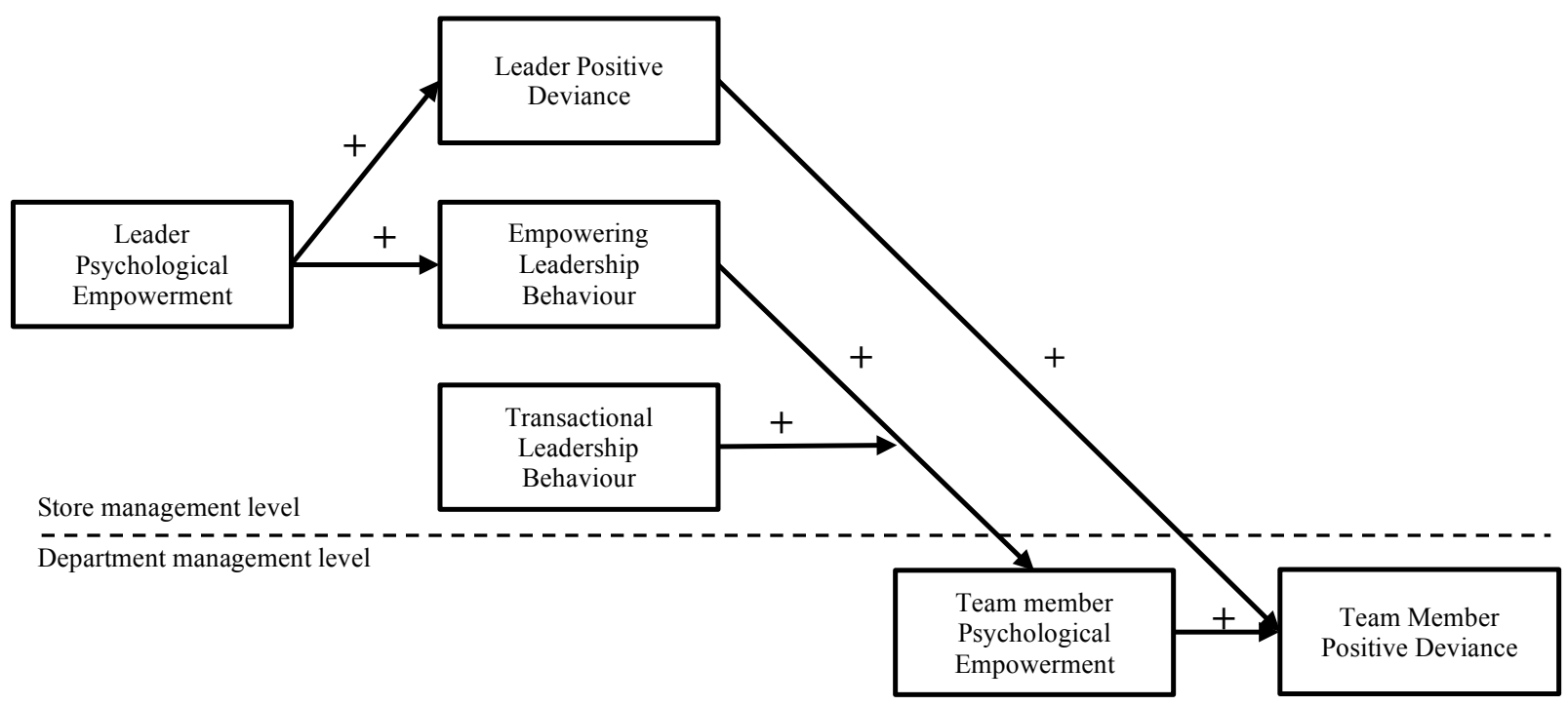

Figure 3. Emergent conceptual model of enablers of positive deviance 
instill a sense of control and motivation (i.e. psychological empowerment) in team members. Noncontingent rewards, or punishments, on the other hand, quickly eroded motivation (e.g., "what are you having a break for now?!" "I'm just drinking water, that's not a break" "well buy yourself a bottle of water and take it with you, I don't pay you for walking here to drink water; if I pay all 185 to walk here, what would happen to my wage budget?!". When leaders empowered their team without stimulating compliance to crucial rules by means of contingent rewards, punishment and monitoring employees also seemed to lose their sense of control over their job. In turn, they were less likely to alter the way they executed tasks in order to improve them, i.e. engage in positive deviant behavior.

\section{Discussion}

The findings of this study suggest that leaders can stimulate the emergence of positive deviance by (1) deviating themselves and (2) combining empowering and consistent transactional leadership styles. Indeed, we found that when leaders feel empowered themselves, they are more likely to positively deviate and - in doing so - they stimulate positive deviance in their teams.

The fact that we found empowering leadership to be so important was somewhat surprising, since the literature suggested that transformational leadership behaviors would play a more important role. However, transformational leadership behaviors were not specifically found to be closely related to positive deviance in our setting. Empowering and transformation leadership behaviors show many similarities, but one key difference may explain these results in the context of positive deviance: empowering leadership aims to involve employees in decision making and stimulate autonomy, while transformational leadership focuses more on being a charismatic and strong leader, which has a dual effect of creating both empowerment and dependency [20]. That dependency and the identification with a strong transformational leader may keep team members from taking initiative to deviate from institutionalized ways of working.

Our findings do corroborate previous research that highlighted the role of empowerment in the emergence of positive deviance $[15,29,42,48]$, but in our setting we found that an optimal balance between two distinct leadership styles stimulated empowerment and positive deviance; more specifically, two leadership styles that are traditionally assumed to relate differently to compliance: transactional leadership primarily serves to stimulate compliance, while empowering leadership stimulates autonomy. Despite this apparent contradiction, we found that the interaction between both styles best explained the emergence of positive deviance. Leaders that were very consistent in their rewards and reprimands and that kept a tight control over processes, yet at the same time invited employees to actively participate in design making and in optimizing work design appeared to stimulate the highest degree of positive deviance. This finding suggests that, either, the transactional leadership behaviors are focused on compliance to certain critical rules or norms, yet allow empowerment elsewhere, or-as suggested by Grant and Parker [16]-the transactional leadership behaviors free up the necessary mental energy to behave in more innovative ways. This observation is also in line with Juillerat's [18] proposition that formalization in combination with motivating and rich work contexts enables positive behavior. At the same time, this observation suggests that 'deviance' may not be the most appropriate term to describe the positive behavior we observed. Sonenshein [38] found that creativity can emerge within routines through a process of simultaneous personalization and depersonalization. Similarly, Juillerat [18] proposed that work can be both standardized and allow for empowerment. Perhaps, when managers exhibit agency in personalizing routines and empower their team members to do the same, deviance seizes to be deviance and the duality of personalization and depersonalization that Sonenshein [38] refers to emerges: innovative changes become endogenous to the work routines, rather than to deviate from them. Or, should we interpret the 'norm' as the depersonalized routine, to which adherence is stimulated by transactional leadership, and is 'deviance' merely the personalization of the routine that empowering leaders stimulate?

\section{Conclusion}

In this paper we reported on a conversion mixed methods field study to explore how leadership by store managers enables the emergence of positive deviance in their departments. Based on both qualitative and quantitative analyses of data gathered in 17 branches of a large Australian retailer, we constructed a conceptual multi-level model that suggests that the emergence of positive deviance can be stimulated by empowering team members while at the same time stimulating compliance to critical organizational processes.

Several limitations bound our study. First, we needed to define our operationalization of performance. We chose a multi-dimensional view of performance akin to the balanced scorecard. However, positive deviance could also be defined in terms of other metrics, such as the employee satisfaction or 
process innovation. Such choices would lead to different findings and in turn a different model.

Second, our field work is bounded by the container of one organization. Third, our work has been inductive and interpretive so far, quantitative evaluation remains outstanding at this point.

Despite these limitations, we hope that our work can spark more research into positive deviance and how leadership and other contextual factors enable its emergence.

\section{References}

[1] J. A. Arnold, S. Arad, J. A. Rhoades and F. Drasgow, "The empowering leadership questionnaire: the construction and validation of a new scale for measuring leader behaviors", Journal of Organizational Behavior, 21 (2000), pp. 249-269.

[2] R. J. Bennett and S. L. Robinson, "Development of a measure of Workplace Deviance", Journal of Applied Psychology, 85 (2000), pp. 349-360.

[3] M. M. Bergman, Hermeneutic Content Analysis: Textual and Audiovisual Analyses within a Mixed Methods Framework, in A. Tashakkori and C. Teddlie, eds., Handbook for mixed methods for social and behavioural science, SAGE Publications, Inc., Thousand Oaks (CA), 2010.

[4] J. M. Burns, Leadership, Harper \& Row, New York, 1978.

[5] K. Charmaz, Constructing Grounded Theory: A Practical Guide through Qualitative Analysis, SAGE Publications Inc., Thousand Oaks, CA, 2006.

[6] G. Chen, B. L. Kirkman, R. Kanfer, D. Allen and B. Rosen, "A multilevel study of leadership, empowerment, and performance in teams", Journal of Applied Psychology, 92 (2007), pp. 331-346.

[7] J. Cordery and S. K. Parker, Work Design: Creating Jobs and Roles that Promote Individual Effectiveness, in S. W. J. Kozlowski, ed., The Oxford Handbook of Organizational Psychology, Oxford University Press, New York, 2012.

[8] I. T. Coyne, "Sampling in qualitative research. Purposeful and theoretical sampling; merging or clear boundaries?", Journal of Advanced Nursing, 26 (1997), pp. 623-630.

[9] K. Dewettinck and M. van Ameijde, "Linking leadership empowerment behaviour to employee attitudes and behavioural intentions - Testing the mediating role of psychological empowerment", Personnel Review, 40 (2011), pp. 284-305.

[10] C. Dubelaar, M. Bhargava and D. Ferrarin, "Measuring retail productivity; What really matters?", Journal of Business Research (2002), pp. 417- 426.

[11] D. C. Feldman, "The Development and Enforcement of Group Norms", The Academy of Management Review, 9 (1984), pp. 47-53.
[12] K. H. Fong and E. Snape, "Empowering Leadership, Psychological Empowerment and Employee Outcomes: Testing a Multi-level Mediating Model", British Journal of Management (2014), pp. 126-138.

[13] C. M. Ford and D. A. Gioia, "Factors influencing creativity in the domain of managerial decision making", Journal of Management, 26 (2000), pp. 705-732.

[14] B. L. Galperin and R. J. Burke, "Uncovering the relationship between workaholism and workplace destructive and constructive deviance: an exploratory study", The International Journal of Human Resource Management, 17 (2006), pp. 331-347.

[15] B. L. Galperin, "Exploring the Nomological Network of Workplace Deviance: Developing and Validating a Measure of Constructive Deviance", Journal of Applied Social Psychology, 42 (2012), pp. 2988-3025.

[16] A. M. Grant and S. K. Parker, "Redesigning Work Design Theories: The Rise of Relational and Proactive Perspectives", The Academy of Management Annals, 3 (2009), pp. 317-375.

[17] T. A. Judge and R. F. Piccolo, "Transformational and Transactional Leadership: A Meta-Analytic Test of Their Relative Validity", Journal of Applied Psychology, 89 (2004), pp. 755-768.

[18] T. L. Juillerat, "Friends, not foes?: Work design and formalization in the modern work context", Journal of Organizational Behavior, 31 (2010), pp. 216-239.

[19] R. S. Kapland and D. P. Norton, The balanced scorecard: translating strategy into action., Harvard Business School Press, Boston, 1996.

[20] R. Kark, B. Shamir and G. Chen, "The two faces of transformational leadership: empowerment and dependency", Journal of applied psychology, 88 (2003), pp. 246.

[21] C. D. Kerns, "Promoting and Managing Positivity: A Coaching Approach", Business Renaissance Quarterly, 6 (2011), pp. 25-49.

[22] Y. M. Kim, M. Heerey and A. Kols, "Factors that enable nurse-patient communication in a family planning context: A positive deviance study", International Journal of Nursing Studies, 45 (2008), pp. 1411-1421.

[23] K. M. Kura, F. M. Shamsudin and A. Chauhan, "Organisational trust as a mediator between perceived organisational support and constructive deviance", International Journal of Business and Society, 17 (2016), pp. $1-18$.

[24] M. Lavine and K. Cameron, "From weapons to wildlife: Positive organizing in practice", Organizational Dynamics, 41 (2012), pp. 135-145.

[25] B. Leavy, "Leading adaptive change by harnessing the power of positive deviance", Strategy \& Leadership, 39 (2011), pp. 18-27.

[26] R. C. Liden, S. J. Wayne and R. T. Sparrowe, "An examination of the mediating role of psychological empowerment on the relations between the job, interpersonal relationships, and work outcomes", Journal of Applied Psychology, 85 (2000), pp. 407-416. 
[27] E. Lieber and T. S. Weisner, Meeting the practical challenges of mixed methods research, in A. Tashakkori and C. Teddlie, eds., Sage handbook of mixed methods research in social and behavioral research, Sage, Thousand Oaks, CA, 2010, pp. 559-280.

[28] W. Mertens, J. Recker, T. Kohlborn and T.-F. Kummer, "A Framework for the Study of Positive Deviance in Organizations", Deviant Behavior (2016), pp. 1-20.

[29] W. Mertens, J. Recker, T.-F. Kummer, T. Kohlborn and S. Viaene, "Constructive deviance as a driver for performance in retail", Journal of Retailing and Consumer Services, 30 (2016), pp. 193-203.

[30] J. P. Meyer and N. J. Allen, "A three-component conceptualization of organizational commitment", Human Resource Management Review, 1 (1991), pp. 61.

[31] J. P. Meyer, D. J. Stanley, L. Herscovitch and L. Topolnytsky, "Affective, Continuance, and Normative Commitment to the Organization: A Meta-analysis of Antecedents, Correlates, and Consequences", Journal of Vocational Behavior, 61 (2002), pp. 20-52.

[32] R. T. Pascale and J. Sternin, "Your company's secret change agents", Harvard Business Review, May 2005 (2005).

[33] P. M. Podsakoff, W. H. Bommer, N. P. Podsakoff and S. B. MacKenzie, "Relationships between leader reward and punishment behavior and subordinate attitudes, perceptions, and behaviors: A meta-analytic review of existing and new research", Organizational Behavior and Human Decision Processes, 99 (2006), pp. 113-142.

[34] H.-G. Ridder, C. Hoon and A. McCandless Baluch, "Entering a Dialogue: Positioning Case Study Findings towards Theory", British Journal of Management, 25 (2014), pp. 373-387.

[35] S. E. Seibert, S. R. Silver and W. A. Randolph, "Taking Empowerment to the Next Level: a Multiple-Level Model of Empowerment, Performance, And Satisfaction", Academy of Management Journal, 47 (2004), pp. 332-349.

[36] S. E. Seibert, G. Wang and S. H. Courtright, "Antecedents and consequences of psychological and team empowerment in organizations: A meta-analytic review", Journal of Applied Psychology, 96 (2011), pp. 981-1003.

[37] W. Seidman and M. McCauley, "Positive Deviants Rule!", Cutter IT Journal, 21 (2008), pp. 16-20.

[38] S. Sonenshein, "Routines and Creativity: From Dualism to Duality", Organization Science, 27 (2016), pp. 739-758.

[39] G. M. Spreitzer, "Psychological Empowerment in the workplace: dimensions, measurement and validation", Academy of Management Journal, 38 (1995), pp. 1442-1465.

[40] G. M. Spreitzer, S. C. De Janasz and R. E. Quinn, "Empowered to lead: the role of psychological empowerment in leadership", Journal of Organizational Behavior, 20 (1999), pp. 511-526.

[41] G. M. Spreitzer and S. Sonenshein, Positive deviance and extraordinary organizing, in K. Cameron, J. Dutton and R. Quinn, eds., Positive organizational scholarship, BerrettKoehler, San Francisco, 2003, pp. 207-224.
[42] G. M. Spreitzer and S. Sonenshein, "Toward the Construct Definition of Positive Deviance", American Behavioral Scientist, 47 (2004), pp. 828-847.

[43] G. M. Spreitzer and D. Doneson, Musings on the past and future of employee empowerment, in T. Cummings, ed., Handbook of Organizational Development, Sage Publishing, London, 2005.

[44] G. M. Spreitzer, Taking Stock: A Review of More Than Twenty Years of Research on Empowerment at Work, in C. Cooper and J. Barling, eds., The Handbook of Organizational Behavior, Sage Publications, 2008.

[45] A. Tashakkori and C. Teddlie, SAGE handbook of mixed methods in social and behavioral research, in A. Tashakkori and C. Teddlie, eds., Handbook for mixed methods for social and behavioural science, SAGE Publications, Inc., Thousand Oaks (CA), 2010.

[46] A. Tashakkori, C. Teddlie and M. C. Sines, Utilizing Mixed Methods in Psychological Research, in I. B. Weiner, J. A. Schinka and W. F. Velicer, eds., Handbook of Psychology, Volume 2, Research Methods in Psychology, John Wiley \& Sons, Inc., Hoboken, New Jersey, 2013.

[47] C. Urquhart, Grounded Theory for Qualitative Research, SAGE, London, 2013.

[48] A. K. Vadera, M. G. Pratt and P. Mishra, "Constructive Deviance in Organizations : Integrating and Moving Forward", Journal of Management, 39 (2013), pp. 12211276.

[49] J. L. Walls and A. J. Hoffman, "Exceptional boards: Environmental experience and positive deviance from institutional norms", Journal of Organizational Behavior, 34 (2013), pp. 253-271.

[50] D. E. Warren, "Constructive and Destructive Deviance in Organizations", Academy of Management Review, 28 (2003), pp. 622-632.

[51] G. Yukl, "Effective Leadership Behaviour: What We Know and What Questions Need More Attention", Academy of Management Perspectives, November (2012), pp. 66-82.

[52] X. Zhang and K. M. Bartol, "Linking empowering leadership and employee creativity: the influence of psychological empowerment, intrinsic motivation, and creative process engagement", Academy of Management Journal, 53 (2010), pp. 107-128.

[53] W. Zheng, S. Kaur and W. Jun, "New development of organizational commitment: A critical review (1960-2009)", African Journal of Business Management, 4 (2010), pp. 1220.

[54] J. Zhou and J. M. George, "Awakening employee creativity: The role of leader emotional intelligence", Leadership Quarterly, 14 (2003), pp. 545-568. 